\title{
Adding radiation to induction chemotherapy does not improve survival of patients with operable clinical N2 non-small cell lung cancer
}

\author{
Chi-Fu Jeffrey Yang, MD, ${ }^{a}$ Brian C. Gulack, MD, ${ }^{a}$ Lin Gu, MS, ${ }^{b}$ Paul J. Speicher, MD, ${ }^{a}$ \\ Xiaofei Wang, PhD, ${ }^{b}$ David H. Harpole, MD, ${ }^{a}$ Mark W. Onaitis, MD, ${ }^{a}$ Thomas A. D'Amico, MD, ${ }^{a}$ \\ Mark F. Berry, MD, MHS, ${ }^{c}$ and Matthew G. Hartwig, MD
}

\begin{abstract}
Objective: Radiotherapy is commonly used in induction regimens for patients with non-small cell lung cancer with operable mediastinal nodal disease, although evidence has not shown a benefit over induction chemotherapy alone. We compared outcomes between induction chemotherapy and induction chemoradiation using the National Cancer Data Base.
\end{abstract}

Methods: Induction radiation use and survival of patients who underwent lobectomy or pneumonectomy after induction chemotherapy for clinical T1-3N2M0 non-small cell lung cancer in the National Cancer Data Base from 2003 to 2006 were assessed using logistic regression, general linear regression, Kaplan-Meier, and Cox proportional hazard analysis.

Results: Of 1362 patients who met study criteria, 834 (61\%) underwent induction chemoradiation and 528 (39\%) underwent induction chemotherapy. Lobectomy was performed in $82 \%$ of patients $(n=1111)$, and pneumonectomy was performed in $18 \%$ of patients $(n=251)$. Pneumonectomy was performed more often after induction chemoradiation than after induction chemotherapy $(20 \%$ vs $16 \%, P=.04)$. Downstaging from N2 to N0/N1 was more common with induction chemoradiation compared with induction chemotherapy $(58 \%$ vs $46 \%, P<.01$ ), but 5 -year survival of patients receiving induction chemoradiation and patients receiving induction chemotherapy was similar in unadjusted analysis ( $41 \%$ vs $41 \%, P=.41$ ). In multivariable analysis, the addition of radiation to induction chemotherapy also was not associated with a survival benefit (hazard ratio, $1.03 ; 95 \%$ confidence interval, $0.89-1.18 ; P=.73$ ).

Conclusions: Induction chemoradiation is used in the majority of patients with non-small cell lung cancer with $\mathrm{N} 2$ disease who undergo induction therapy before surgical resection, but it is not associated with improved survival compared with induction chemotherapy. (J Thorac Cardiovasc Surg 2015;150:1484-93)

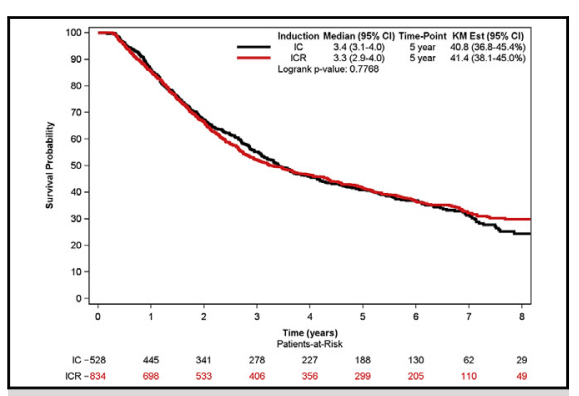

Overall survival after induction therapy followed by surgery for stage IIIA-N2 NSCLC.

\section{Central Message}

ICR is not associated with improved survival when compared with IC for operable cN2 NSCLC.

\section{Perspective}

Radiation is commonly used in induction regimens for patients with NSCLC with operable mediastinal nodal disease, although evidence has not shown benefit over IC alone. We compared the outcomes between IC and ICR using the NCDB. ICR is not associated with improved survival compared with IC for operable cN2 NSCLC.

See Editorial Commentary page 1494.

See Editorial page 1407.

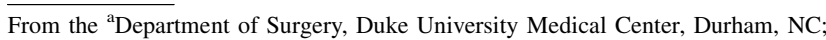
${ }^{b}$ Department of Biostatistics, Duke University, Durham, NC; and ${ }^{\mathrm{c}}$ Department of Cardiothoracic Surgery, Stanford University Medical Center, Stanford, Calif.

This work was supported by the National Institutes of Health funded Cardiothoracic Surgery Trials Network (M.F.B. and M.G.H), 5U01HL088953-05, and by the American College of Surgeons Resident Research Scholarship (C.J.Y.).

C.J.Y. and B.C.G. contributed equally to this study.

M.F.B. and M.G.H. are co-senior authors.

Read at the 95th Annual Meeting of The American Association for Thoracic Surgery, Seattle, Washington, April 25-29, 2015.

Received for publication Jan 19, 2015; revisions received May 5, 2015; accepted for publication June 3, 2015; available ahead of print Aug 7, 2015.

Address for reprints: Matthew G. Hartwig, MD, Duke University Medical Center, DUMC Box \#3863, Durham, NC 27710 (E-mail: matthew.hartwig@duke.edu).

$0022-5223 / \$ 36.00$

Copyright (c) 2015 by The American Association for Thoracic Surgery

http://dx.doi.org/10.1016/j.jtcvs.2015.06.062
The optimal induction strategy for patients with stage IIIAN2 non-small cell lung cancer (NSCLC) who are selected for surgery is not well established. Induction chemotherapy (IC) has been shown to definitively improve survival over the primary use of surgery. ${ }^{1,2}$ However, the benefit of using induction chemoradiotherapy (ICR) compared with IC alone is not as clear. Only a handful of studies have compared IC and ICR for stage IIIA-N2 NSCLC, and the two largest and most recent randomized controlled trials evaluating IC and ICR were both performed in Europe with induction regimens that likely do not reflect current US practice. ${ }^{3,4}$ Of the limited available data, ICR has 


\section{Abbreviations and Acronyms \\ $\mathrm{AOR}=$ adjusted odds ratio \\ $\mathrm{CDCC}=$ Charlson/Deyo comorbidity condition \\ $\mathrm{CI}=$ confidence interval \\ HR = hazard ratio \\ IC = induction chemotherapy \\ ICR = induction chemoradiotherapy \\ $\mathrm{NCDB}=$ National Cancer Data Base \\ NSCLC $=$ non-small cell lung cancer}

been found to be associated with a higher rate of mediastinal nodal downstaging and histopathologic response but also increased acute toxicity and cost. ${ }^{3,5,6}$ More important, adding radiotherapy to IC regimens has not been shown to improve overall survival.

Considering the lack of definitive evidence that establishes an optimal preoperative regimen, clinical practice not surprisingly varies across the United States. ${ }^{8}$ There is no consensus on the best strategy in the National Cancer Center Network, as reflected by the fact that $50 \%$ of member institutions use ICR and 50\% use IC alone. ${ }^{6}$ The present study was undertaken to improve the level of evidence available to guide induction therapy choice for patients with NSCLC with N2 disease, considering that a large randomized prospective trial that adequately compares ICR and IC may never happen. The specific purpose of this study was to test the hypothesis that ICR does not improve survival over IC alone in patients with operable stage IIIA-cN2 NSCLC using a national population-based oncology outcomes database.

\section{MATERIALS AND METHODS National Cancer Database}

The National Cancer Data Base (NCDB) is jointly managed by the American College of Surgeons Commission on Cancer and the American Cancer Society, and captures approximately $70 \%$ of all newly diagnosed cases of cancer in the United States and Puerto Rico. ${ }^{9}$ Clinical staging information is directly recorded in the NCDB using American Joint Committee on Cancer 6th edition TNM classifications for the years of study inclusion (2003-2006). ${ }^{10}$

\section{Study Design}

This NCDB analysis was approved by the Duke University Institutional Review Board. From a de-identified NCDB participant user file, we selected all patients in the NCDB diagnosed with clinical T1-3 N2, M0 NSCLC from January 1, 2003, to December 31, 2006, and identified using International Classification of Diseases for Oncology, 3rd edition histology and topography codes. This study period was chosen for 2 primary reasons: (1) The Charlson/Deyo comorbidity condition (CDCC) score was not recorded before 2003, and (2) at the time of our analysis, long-term survival data were available for patients diagnosed up to the end of 2006. Within this population, we abstracted patients treated with IC followed by surgery (IC group) or combination ICR followed by surgery (ICR group). Exclusion criteria included nonmalignant pathology, history of unrelated malignancy, $\mathrm{N} 3$ or metastatic disease, and patients who received no IC or received only palliative treatment. The primary outcome was overall survival. Secondary outcomes included rates of nodal downstaging, 30-day mortality and readmission, hospital length of stay, and regional lymph nodes examined. Of note, the NCDB does not have data regarding specific perioperative outcomes; however, 30-day readmission and hospital length of stay may be interpreted as surrogate markers for postoperative morbidity. We also examined the practice patterns of hospitals to determine the percentage of patients who undergo IC or ICR within each hospital. A hospital that practices "primarily" IC or chemoradiation was defined as a hospital where $80 \%$ to $100 \%$ of their patients underwent IC or ICR.

\section{Statistical Analysis}

Patients were grouped according to induction therapy regimen (IC or ICR), and comparisons of baseline characteristics and unadjusted outcomes were performed using the Wilcoxon rank-sum test for continuous variables and Pearson's chi-square test for discrete variables. A logistic regression model was developed to identify predictors of induction radiation use. Variables in the model included age, clinical $\mathrm{T}$ status, CDCC score (which is recorded as 0,1 , or 2), sex, race, treatment facility type, insurance type, histology, and tumor location. Median survival and 5 -year survival were estimated by the Kaplan-Meier product limit approach, both for the overall cohort and for the subgroup of patients treated with lobectomy.

A multivariable linear regression model was used to identify variables that were significantly associated with the number of lymph nodes examined. Variables in the model included age, tumor size, CDCC score, sex, race, facility type, histology, and tumor location.

A Cox proportional hazards model was used to compare overall survival between groups, adjusting for induction radiation use, type of operation (lobectomy vs pneumonectomy), insurance type (private, Medicare/Medicaid, other government, uninsured, and unknown), age, gender, race, CDCC score, clinical T status, facility type, histology (adenocarcinoma, squamous cell carcinoma, and others), and tumor location.

Subgroup analyses were performed to examine the impact of the extent of surgical resection on outcomes, and the survival analysis described earlier was repeated on the subgroup of patients whose surgical resection was lobectomy and on the subgroup of patients whose surgical resection was pneumonectomy. Further subgroup analyses were performed to examine the impact of downstaging on survival. We also performed subgroup analyses of patients who had clinical T1N2, T3N2, and pathologic T0N0 who underwent lobectomy.

In another subgroup analysis, we examined the long-term survival of patients who received ICR using a Kaplan-Meier analysis, stratified by the dose of induction radiation given $(<4000,4001-5000,5001-6000$, and $>6000$ cGy). We then performed a multivariable Cox proportional hazards analysis of only the ICR cohort of patients, adjusting for the covariates of induction radiation dose, type of operation (lobectomy vs pneumonectomy), insurance type (private, Medicare/Medicaid, other government, uninsured, and unknown), age, gender, race, CDCC score and clinical $\mathrm{T}$ status, facility type, histology, and tumor location. All statistical analyses were performed using SAS for Windows, Version 9.3 (SAS Institute Inc, Cary, NC).

\section{RESULTS}

Between 2003 and 2006, 1362 patients were diagnosed with clinical T1-T3 N2 M0 NSCLC and had undergone lobectomy or pneumonectomy (Figure 1). Of these, 834 $(61 \%)$ were treated using ICR and surgery and 528 $(39 \%)$ were treated using IC and surgery. Approximately $77 \%$ of hospitals used primarily IC or primarily ICR as their induction therapy strategy. 


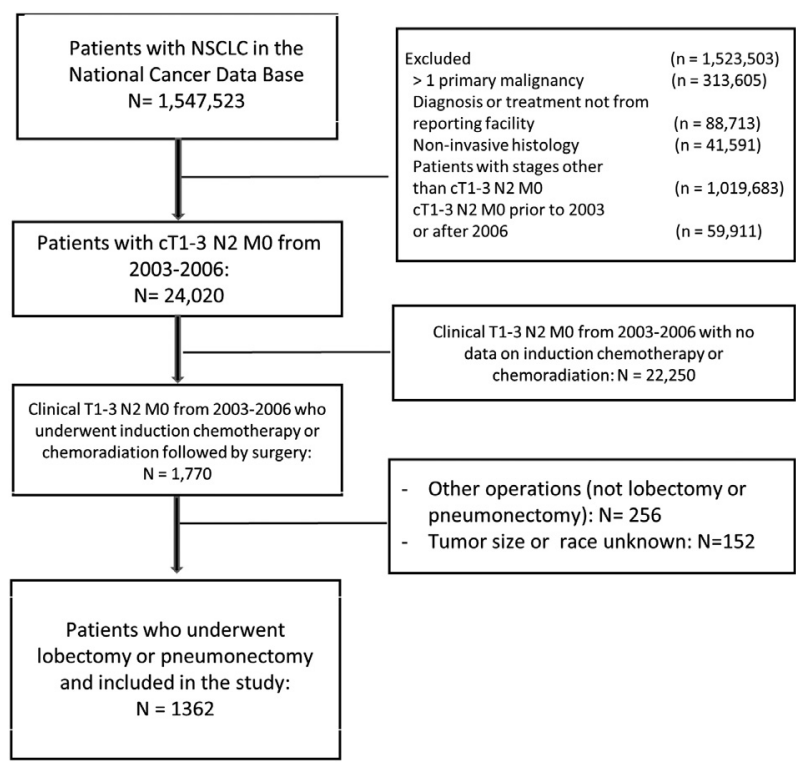

FIGURE 1. Consort diagram showing schema of study subject selection. NSCLC, Non-small cell lung cancer.

Tables 1 and 2 show the preoperative, demographic, perioperative, and postoperative data of the two groups. The patients who received ICR were younger than the patients who received IC, but there were no statistically significant differences between the two groups in regard to sex, race, CDCC score, and insurance status. The ICR group had a larger tumor size and a higher clinical $\mathrm{T}$ status.

More patients in the ICR group underwent pneumonectomy compared with the IC group $(20.1 \%$ vs $15.7 \%$,
$P=.04)$. Adjuvant radiation was used in $31 \%$ of patients in the IC group. Of the patients who underwent an operation for pT0N0, 48 underwent a lobectomy and 8 underwent a pneumonectomy.

Patient characteristics that were associated with induction radiation included younger age (adjusted odds ratio [AOR], 0.97/year; 95\% confidence interval [CI], $0.96-0.99 ; P<.0001$ ), T status (AOR, $1.47 ; 95 \% \mathrm{CI}$, 1.12-1.92; $P=.005$ and AOR, 2.25; 95\% CI, 1.52-3.35; $P<.0001$ for T2 and T3 tumors, respectively, compared with T1), and treatment at a nonacademic community cancer program (AOR, 2.00; 95\% CI, 1.25-3.21; $P=.004$ ) and comprehensive cancer program (AOR, 1.72; 95\% CI, 1.36-2.18; $P<.0001)$.

After multivariable adjustment, use of induction radiation was found to be significantly associated with fewer lymph nodes examined (regression coefficient [standard error], -1.9 [0.54]; $P=.001$ ).

Overall $\mathrm{T}$ and $\mathrm{N}$ downstaging was more common with ICR when compared with IC. Although pathologic M1 disease was uncommon overall, there was a higher number of patients with pathologic M1 disease in the IC group compared with the ICR group (11 [2.1\%] vs $4[0.5 \%]$, $P<.01)$. There were no further details in the NCDB regarding the site of distant metastases or type of M1 disease found. Hospital readmission in 30 days and hospital length of stay were similar in both groups (Table 2). There were no significant differences in perioperative deaths between the IC and ICR groups (Table 2).

The median follow-up was 6.6 years (interquartile range, 5.3-7.3 years). Kaplan-Meier analysis demonstrated

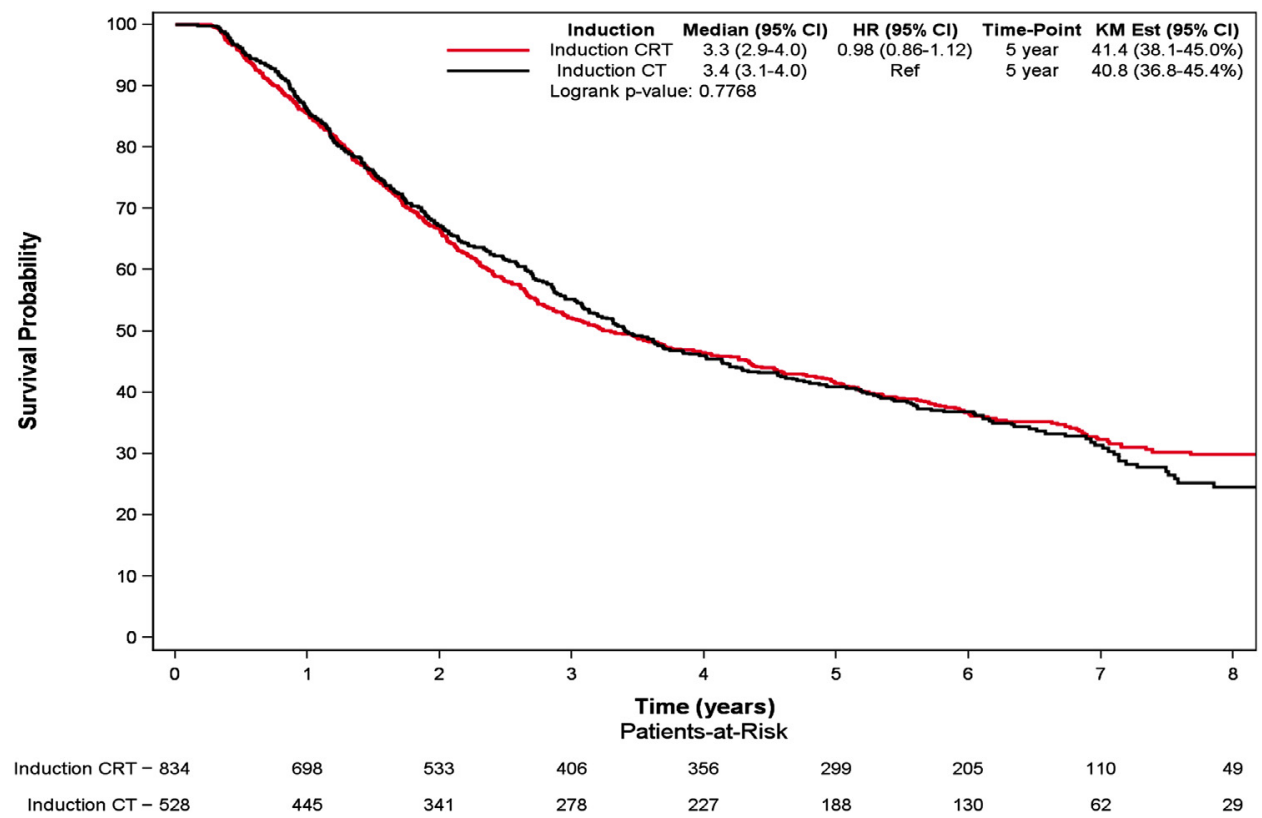

FIGURE 2. Overall survival of patients with stage IIIA-N2 NSCLC who underwent IC versus ICR followed by major lung resection. $C I$, Confidence interval; $H R$, hazard ratio; $K M$, Kaplan-Meier, $C R T$, chemoradiation; $C T$, chemotherapy. 
TABLE 1. Preoperative and demographic characteristics

\begin{tabular}{|c|c|c|c|}
\hline & $\begin{array}{c}\text { IC } \\
(\mathbf{N}=\mathbf{5 2 8})\end{array}$ & $\begin{array}{c}\text { ICR } \\
(\mathbf{N}=\mathbf{8 3 4})\end{array}$ & $\begin{array}{c}P \\
\text { value* }\end{array}$ \\
\hline Patient age (y) & & & $<.01$ \\
\hline Mean (SD) & $62.2(10.0)$ & $59.9(9.8)$ & \\
\hline Median, IQR & $63(55.0,70.0)$ & $61(53.0,67.0)$ & \\
\hline Sex, n $(\%)$ & & & .23 \\
\hline Male & $250(47.3 \%)$ & $423(50.7 \%)$ & \\
\hline Female & $278(52.7 \%)$ & $411(49.3 \%)$ & \\
\hline Race, n (\%) & & & .80 \\
\hline White & $475(90.0 \%)$ & $750(89.9 \%)$ & \\
\hline Black & $35(6.6 \%)$ & $60(7.2 \%)$ & \\
\hline Other & $18(3.4 \%)$ & $24(2.9 \%)$ & \\
\hline CDCC score, $\mathrm{n}(\%)$ & & & .83 \\
\hline 0 & $371(70.3 \%)$ & $596(71.5 \%)$ & \\
\hline 1 & $129(24.4 \%)$ & $199(23.9 \%)$ & \\
\hline 2 & $28(5.3 \%)$ & $39(4.7 \%)$ & \\
\hline Insurance type, $\mathrm{n}(\%)$ & & & .55 \\
\hline Uninsured & $15(2.8 \%)$ & $17(2.0 \%)$ & \\
\hline Private & $261(49.4 \%)$ & $449(53.8 \%)$ & \\
\hline Medicare/aid & $232(43.9 \%)$ & $340(40.8 \%)$ & \\
\hline Other government & $9(1.7 \%)$ & $13(1.6 \%)$ & \\
\hline Unknown & $11(2.1 \%)$ & $15(1.8 \%)$ & \\
\hline Clinical T stage, n (\%) & & & $<.01$ \\
\hline $\mathrm{T} 1$ & $155(29.4 \%)$ & $176(21.1 \%)$ & \\
\hline $\mathrm{T} 2$ & $318(60.2 \%)$ & $512(61.4 \%)$ & \\
\hline $\mathrm{T} 3$ & $55(10.4 \%)$ & $146(17.5 \%)$ & \\
\hline Facility type, n (\%) & & & $<.01$ \\
\hline $\begin{array}{l}\text { Community cancer } \\
\text { program }\end{array}$ & $29(5.5 \%)$ & $67(8.0 \%)$ & \\
\hline $\begin{array}{l}\text { Comprehensive } \\
\text { community } \\
\text { cancer program }\end{array}$ & $202(38.3 \%)$ & $406(48.7 \%)$ & \\
\hline $\begin{array}{l}\text { Academic/research } \\
\text { program }\end{array}$ & $295(55.9 \%)$ & $355(42.6 \%)$ & \\
\hline $\begin{array}{l}\text { Other specified types of } \\
\text { cancer programs }\end{array}$ & $2(0.4 \%)$ & $6(0.7 \%)$ & \\
\hline Tumor location, n (\%) & & & .11 \\
\hline RLL & $87(16.5 \%)$ & $100(12.0 \%)$ & \\
\hline LLL & $33(6.3 \%)$ & $74(8.9 \%)$ & \\
\hline RML & $18(3.4 \%)$ & $20(2.4 \%)$ & \\
\hline RUL & $233(44.1 \%)$ & $374(44.8 \%)$ & \\
\hline LUL & $131(24.8 \%)$ & $212(25.4 \%)$ & \\
\hline Main bronchus & $6(1.1 \%)$ & $15(1.8 \%)$ & \\
\hline Overlapping lesion & $11(2.1 \%)$ & $15(1.8 \%)$ & \\
\hline Other & $9(1.7 \%)$ & $24(2.9 \%)$ & \\
\hline
\end{tabular}

$I C$, Induction chemotherapy; ICR, induction chemoradiotherapy; $S D$, standard deviation; $I Q R$, interquartile range; $C D C C$, Charlson/Deyo comorbidity condition; $R L L$, right lower lobe; $L L L$, left lower lobe; $R M L$, right middle lobe; $R U L$, right upper lobe; $L U L$, left upper lobe. ${ }^{*} P$ values provided are from the Wilcoxon rank-sum test on continuous variables and from the chi-square test on categoric variables.

a 5-year survival of $40.8 \%$ for the IC group and $41.4 \%$ for the ICR group $(P=.41)$ (Figure 2). The multivariable adjusted survival analyses demonstrated that induction radiation use was not associated with improved survival (hazard ratio $[\mathrm{HR}], 1.03 ; 95 \% \mathrm{CI}, 0.89-1.18 ; P=.73$ ) (Table 3).
TABLE 2. Perioperative and postoperative data

\begin{tabular}{|c|c|c|c|}
\hline & $\begin{array}{c}\text { IC } \\
(\mathrm{N}=\mathbf{5 2 8})\end{array}$ & $\begin{array}{c}\text { ICR } \\
(\mathbf{N}=\mathbf{8 3 4})\end{array}$ & $\begin{array}{c}P \\
\text { value* }\end{array}$ \\
\hline Type of surgery, n (\%) & & & .04 \\
\hline Pneumonectomy & $83(15.7 \%)$ & $168(20.1 \%)$ & \\
\hline Lobectomy & $445(84.3 \%)$ & $666(79.9 \%)$ & \\
\hline \multicolumn{4}{|l|}{$\begin{array}{l}\text { Time from induction } \\
\text { therapy to surgery, } \mathrm{d}\end{array}$} \\
\hline Mean (SD) & $97(43)$ & $99(41)$ & .68 \\
\hline Median, IQR & $89(71-113)$ & $88(72-113)$ & \\
\hline Regional lymph nodes examined & & & $<.01$ \\
\hline $\begin{array}{l}\text { No. of patients with } \\
\text { lymph nodes examined }\end{array}$ & 416 & 702 & \\
\hline Median, IQR & $10(4.5-16.0)$ & $7(4.5-16.0)$ & \\
\hline Size of tumor $(\mathrm{cm})$ & & & $<.01$ \\
\hline Mean (SD) & $4.0(2.2)$ & $4.5(3.3)$ & \\
\hline Median, IQR & $3.5(2.5-5.0)$ & $4(2.6-6.0)$ & \\
\hline \multicolumn{4}{|l|}{ Downstaging } \\
\hline T-stage downstaging $\dagger$ & $99(24.2)$ & $214(37.7)$ & $<.01$ \\
\hline $\mathrm{N} 2$ to $\mathrm{N} 0$ downstaging & $136(32.5)$ & $267(45.4)$ & $<.01$ \\
\hline $\mathrm{N} 2$ to $\mathrm{N} 0 / \mathrm{N} 1$ downstaging $\ddagger$ & $190(45.5)$ & $338(57.5)$ & $<.01$ \\
\hline \multicolumn{4}{|l|}{ Margin status, $\mathrm{n}(\%)$} \\
\hline Negative & $469(88.8 \%)$ & $741(87.6 \%)$ & .55 \\
\hline Positive & $42(8.0)$ & $58(7.0)$ & \\
\hline Unknown & $17(3.2)$ & $35(4.2)$ & \\
\hline Histology, n (\%) & & & .14 \\
\hline Adenocarcinoma & $240(45.5 \%)$ & $332(39.8 \%)$ & \\
\hline Squamous & $137(25.9 \%)$ & $219(26.3 \%)$ & \\
\hline Large cell & $22(4.2 \%)$ & $38(4.6 \%)$ & \\
\hline Other & $129(24.4 \%)$ & $245(29.4 \%)$ & \\
\hline Readmission in $30 \mathrm{~d}, \mathrm{n}(\%)$ & $29(5.7 \%)$ & $54(7.0 \%)$ & .38 \\
\hline $\begin{array}{l}\text { Surgical inpatient stay, } \\
\text { days from surgery }\end{array}$ & & & .37 \\
\hline $\begin{array}{l}\text { No. of patients with } \\
\text { available data }\end{array}$ & 466 & 705 & \\
\hline Mean (SD) & $7.0(6.7)$ & $7.4(7.4)$ & \\
\hline Median, IQR & $6(4-8)$ & $6(4-8)$ & \\
\hline \multicolumn{4}{|l|}{ Perioperative mortality, n (\%) } \\
\hline Lobectomy & $6(1.4)$ & $18(2.7)$ & .14 \\
\hline Pneumonectomy & $7(8.4)$ & $10(5.9)$ & .59 \\
\hline
\end{tabular}

$I C$, Induction chemotherapy; $I C R$, induction chemoradiotherapy; $S D$, standard deviaton; $I Q R$, interquartile range. $* P$ values provided are from the Wilcoxon rank-sum test on continuous variables and from the chi-square test on categoric variables. $\dagger$ Includes cases of $\mathrm{T} 1$ to $\mathrm{T} 0, \mathrm{~T} 2$ to $\mathrm{T} 0 / \mathrm{T} 1$, and $\mathrm{T} 3$ to T0/T1/T2. Excludes 385 unknown cases of pathologic $\mathrm{T}$ stage. $\ddagger$ Excludes 356 unknown cases of pathologic $\mathrm{N}$ stage.

\section{Subgroup Analyses}

In a subgroup analysis of only those patients who underwent lobectomy, use of induction radiation was again not associated with a significant difference in long-term survival (5-year survival, $42.3 \%$ vs $44.0 \%$ for the IC and ICR groups, respectively, $P=.54$ ) (Figure 3). After adjustment, this lack of significant survival benefit was maintained (HR, $1.01 ; 95 \% \mathrm{CI}, 0.86-1.18)$.

In a subgroup analysis of only those patients who underwent pneumonectomy, use of induction radiation was again not associated with a significant difference in 
TABLE 3. Independent predictors of survival after Cox proportional hazards adjustment for patients with stage IIIA-N2 non-small cell lung cancer who have undergone induction chemotherapy or chemoradiation followed by lobectomy or pneumonectomy

\begin{tabular}{|c|c|c|c|}
\hline & Hazard ratio & $95 \% \mathrm{CI}$ & $P$ value \\
\hline ICR vs IC & 1.03 & $0.89-1.18$ & .73 \\
\hline Lobectomy vs pneumonectomy & 0.66 & $0.55-0.79$ & $<.001$ \\
\hline \multicolumn{4}{|l|}{ Insurance type (ref = private) } \\
\hline Medicare/aid & 0.99 & $0.84-1.16$ & .87 \\
\hline Other government & 1.70 & $1.07-2.71$ & .02 \\
\hline Uninsured & 2.15 & $1.44-3.20$ & $<.001$ \\
\hline Unknown & 1.27 & $0.77-2.11$ & .35 \\
\hline Age (y) & 1.02 & $1.01-1.03$ & $<.001$ \\
\hline Female vs male & 0.94 & $0.82-1.08$ & .37 \\
\hline \multicolumn{4}{|l|}{ Race $($ ref $=$ white $)$} \\
\hline Black & 0.92 & $0.70-1.20$ & .53 \\
\hline Other & 0.91 & $0.62-1.34$ & .64 \\
\hline \multicolumn{4}{|l|}{ CDCC score $($ ref $=0)$} \\
\hline 1 & 1.12 & $0.96-1.31$ & .16 \\
\hline $2+$ & 1.11 & $0.81-1.52$ & .52 \\
\hline \multicolumn{4}{|l|}{ Clinical $\mathrm{T}$ stage $(\mathrm{ref}=\mathrm{T} 1)$} \\
\hline $\mathrm{T} 2$ & 1.07 & $0.91-1.27$ & .40 \\
\hline $\mathrm{T} 3$ & 1.05 & $0.83-1.33$ & .68 \\
\hline \multicolumn{4}{|l|}{ Facility type (ref $=$ academic $)$} \\
\hline Community & 1.22 & $0.94-1.58$ & .13 \\
\hline Comprehensive & 0.98 & $0.85-1.13$ & .76 \\
\hline \multicolumn{4}{|l|}{ Histology (ref $=$ adenocarcinoma) } \\
\hline Squamous & 0.92 & $0.77-1.10$ & .34 \\
\hline Other & 1.01 & $0.87-1.19$ & .87 \\
\hline \multicolumn{4}{|l|}{ Tumor location $($ ref $=$ RUL) } \\
\hline LLL & 1.43 & $1.12-1.84$ & $<.01$ \\
\hline LUL & 1.17 & $0.99-1.39$ & .08 \\
\hline RLL & 1.45 & $1.18-1.77$ & $<.001$ \\
\hline RML & 1.09 & $0.71-1.67$ & .71 \\
\hline Other & 1.11 & $0.82-1.50$ & .50 \\
\hline
\end{tabular}

$C I$, Confidence interval; $I C$, induction chemotherapy; $I C R$, induction chemoradiotherapy; $C D C C$, Charlson/Deyo comorbidity condition; $R U L$, right upper lobe; $L L L$, left lower lobe; $L U L$, left upper lobe; $R L L$, right lower lobe; $R M L$, right middle lobe.

long-term survival (5-year survival, $33 \%$ vs $32 \%$ for the IC and ICR groups, respectively, $P=.99$ ) (Figure 4). After adjustment, this lack of significant survival benefit was maintained (HR, 1.15; 95\% CI, 0.80-1.65).

Patients who had T-stage downstaging had improved median (4.3 years [95\% CI, 3.6-5.4]) and 5-year survival (46.0\% [95\% CI, 40.5\%-52.3\%]) when compared with patients who did not have T-stage downstaging (median survival of 2.9 years [95\% CI, 2.7-3.3] and 5-year survival of $36.4 \%$ [95\% CI, 32.9-40.3]). Patients with nodal downstaging ( $\mathrm{cN} 2$ to $\mathrm{pN} 1 / \mathrm{N} 0$ ) had improved median (4.0 years [95\% CI, 3.3-4.9]) and 5-year survival (44.8\% [95\% CI, 40.6\%-49.3\%]) when compared with patients who did not have nodal downstaging (median survival, 3.0 [95\% CI, 2.7-3.4] and 5-year survival of 34.4\% [95\% CI, $30.2 \%-39.0 \%]$ ).

There was no significant difference in survival between patients in the IC group who had T-stage downstaging versus patients in the ICR group who had T-stage downstaging (median survival, 4.6 years [95\% CI, 3.6-6.2] vs 4.3 years [95\% CI, 3.2-5.7]; 5-year survival, $46.6 \%$ [95\% CI, 37.4-58.1] vs $45.8 \%$ [ $95 \%$ CI, 39.1-53.5]). For patients with nodal downstaging, there was no significant difference in survival between the IC and ICR groups (median survival, 4.0 years [ $95 \% \mathrm{CI}, 3.3-5.7]$ vs 4.0 years [95\% CI, 2.8-5.2]; 5-year survival, 44.6\% [95\% CI, 37.9-52.4] vs $44.9 \%$ [95\% CI, 39.8-50.7]).

In a subgroup analysis of 310 patients who had cT1N2 NSCLC, there were no significant differences in longterm survival between the groups (5-year survival, $48.9 \%$ [95\% CI, 41.3-57.8] vs $40.6 \%$ [95\% CI, 33.4-49.2] in the IC and ICR groups, respectively; log-rank, $P=.41$ ). In a subgroup analysis of 46 patients who had pT1N0 NSCLC, there were no significant differences in median survival between the groups $(7.6[95 \% \mathrm{CI}, 4.6$-not estimable] vs 8.2 [95\% CI, 4.1-not estimable] years in the IC and ICR groups, respectively; log-rank, $P=.70$ ).

Because the induction chemoradiation cohort had a significantly higher proportion of patients with T3N2, which has been shown to have worse prognosis than T1-T2 N2, we performed a subset analysis of patients with cT3 $\mathrm{cN} 2$ who underwent induction therapy followed by lobectomy and found no significant differences in overall survival between the IC and ICR groups (5-year survival, 45.3 [95\% CI, 31.9-64.3] vs 41.5 [95\% CI, 32.6-52.9], $P=.89$ ).

In addition, we examined the type of radiation that patients with ICR received. Of the 810 patients receiving ICR with available data, 97\% underwent concurrent chemoradiation. A total of 745 of 834 patients had radiation dose data available. A total of 200 patients $(26.9 \%)$ had a radiation dose 4000 cGy or less, 359 patients $(48.2 \%)$ had a dose of 4001 to $5000 \mathrm{cGy}, 124$ patients $(16.6 \%)$ had a dose of 5001 to $6000 \mathrm{cGy}$, and 62 patients $(8.3 \%)$ had a dose greater than $6000 \mathrm{cGy}$. The 5-year survival was 45.8 (95\% CI, 40.8-51.4), 41.5 (95\% CI, 33.5-51.4), 37.6 (95\% CI, 31.4-45.1), and 35.2 (95\% CI, 28.0-44.3) for patients who received ICR undergoing induction radiation doses of 4001 to $5000 \mathrm{cGy}, 5001$ to $6000 \mathrm{cGy}$, less than $4000 \mathrm{cGy}$, and more than $6000 \mathrm{cGy}$, respectively $(P=.058)$. In multivariable analysis, there were no categories of induction radiation dose that were significantly associated with increased survival.

\section{DISCUSSION}

This is the first population-based study and largest observational study to demonstrate that the addition of radiation to IC for operable stage IIIA-cN2 NSCLC is not associated with a significant improvement in overall survival. Although there was a slight predilection for pneumonectomy in the ICR group, this finding remained significant after limiting the analysis to patients who 


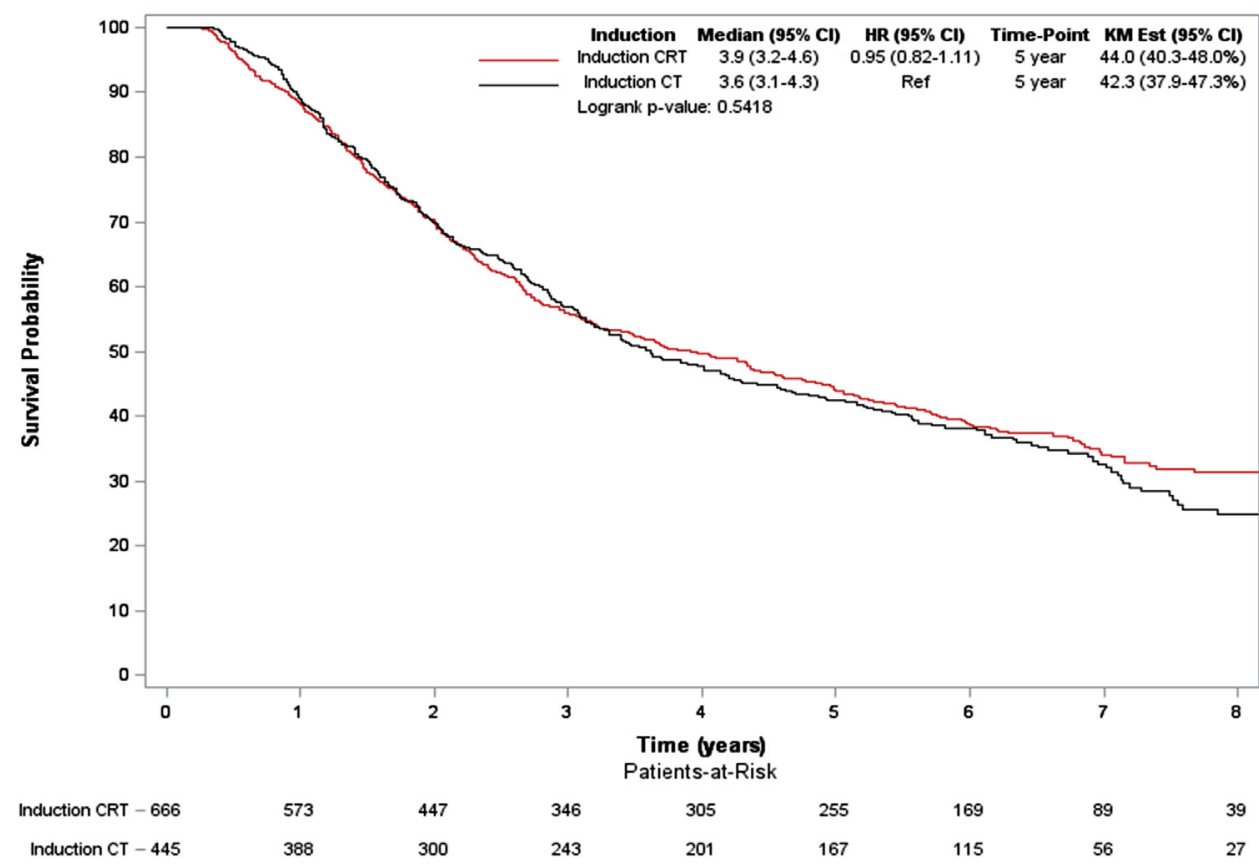

FIGURE 3. Overall survival of patients with stage IIIA-N2 NSCLC who underwent IC versus ICR followed by lobectomy. CI, Confidence interval; $H R$, hazard ratio; $K M$, Kaplan-Meier; $C R T$, chemoradiation; $C T$, chemotherapy.

underwent lobectomy. In addition, we found that there was no difference in length of stay and hospital readmission between the IC and ICR groups, suggesting that perioperative complication rates are similar between the groups. Our primary finding, that induction chemoradiation is not associated with improved survival when compared with IC, is consistent with findings by previous studies limited by smaller sample sizes, $3,11-17$ and adds to the current literature by reporting the results of contemporary "real-world" practice in the United States.

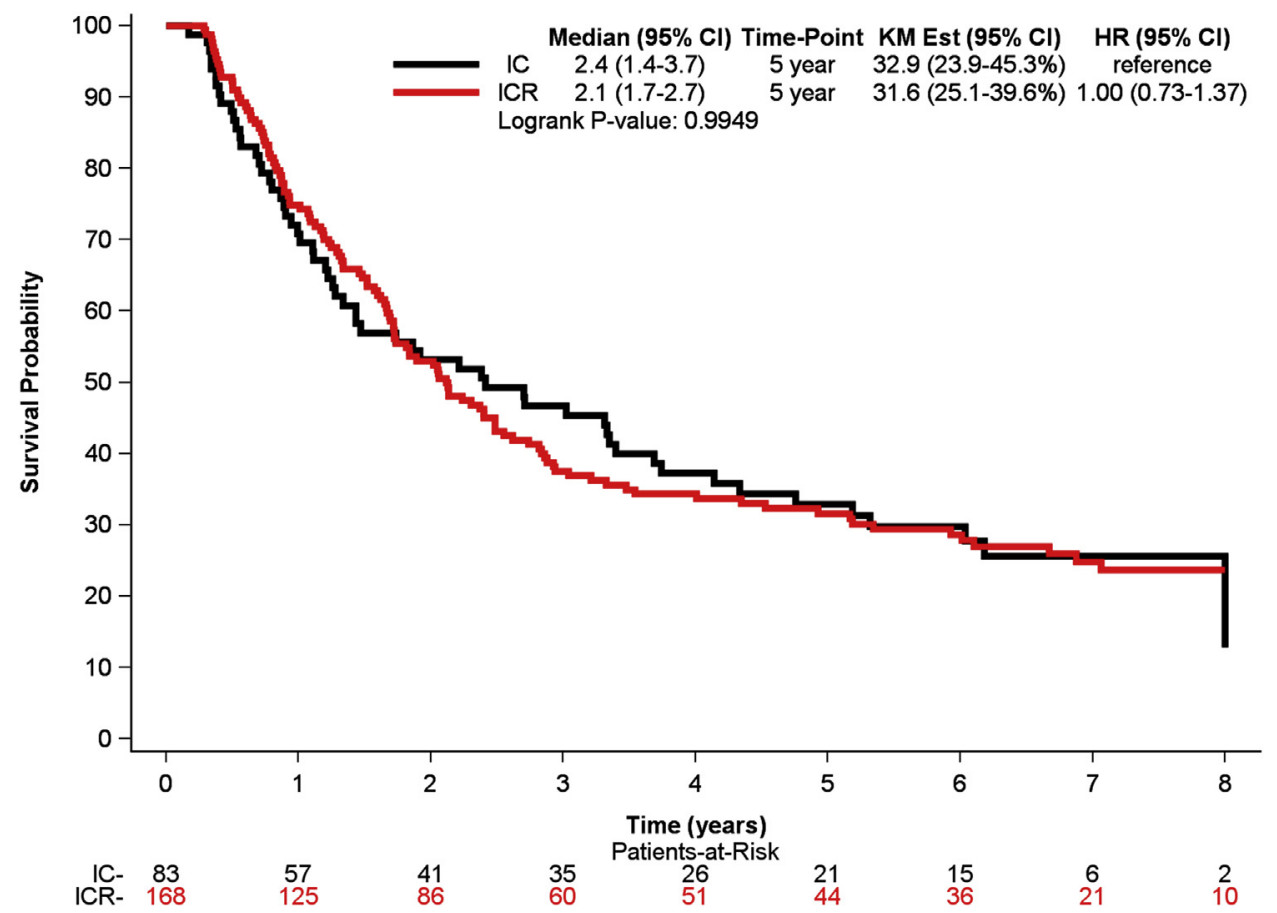

FIGURE 4. Overall survival of patients with stage IIIA-N2 NSCLC who underwent IC versus ICR followed by pneumonectomy. CI, Confidence interval; $K M$, Kaplan-Meier; $H R$, hazard ratio; $I C$, induction chemotherapy; $I C R$, induction chemoradiotherapy. 
Although there was no difference in long-term survival, induction radiation was associated with a significant increase in mediastinal downstaging. This finding confirms existing studies and is thought to represent the key advantage of adding radiation to induction regimens. ${ }^{3,14}$ We also measured the number of lymph nodes collected and found that induction radiation was associated with a significant decrease in the number of lymph nodes examined. It is possible that the decrease in mediastinal downstaging associated with induction radiation was due to fewer overall lymph nodes and stations examinedbecause induction radiation could lead to obliterated planes and more difficult mediastinal lymph node dissections. There also may be the possibility that some surgeons did not perform a complete mediastinal lymph node dissection because they thought the mediastinum was already treated with radiation. An additional consideration is that depending on the institution, multidisciplinary tumor boards may decide against preoperative radiation treatment if there is a high probability that the surgeon can remove all affected nodes at the time of surgery, which could have also resulted in higher numbers of nodes harvested in the IC cohort and a more definitive oncologic operation. However, as reported by previous restaging studies, it is also possible that radiation obliterated more nodal tissue, resulting in fewer viable lymph nodes that could be collected. ${ }^{18}$

In the present study, the outcomes of patients who underwent pneumonectomy after induction therapy were significantly better than those reported by the Intergroup 0139 trial, which described a treatment-related mortality of $26 \%$ for patients undergoing pneumonectomy. ${ }^{19}$ It is unclear why there is this difference in outcomes, but it is important to note that the Intergroup 0139 trial had an accrual period (1994-2001) that was older than the present study time period (2003-2006). Since the 1990s, changes by institutions may have occurred regarding the specific selection criteria for pneumonectomy, extent of evaluation of comorbidity, strategies to protect the bronchial stump, perioperative fluid administration, use of elective postoperative mechanical ventilation, and use of 3-dimensional radiation planning. ${ }^{20-24}$ These changes or variations in practice patterns noted may explain the better outcomes reported in the present study.

Our results can be used to aid the decision process when patients and providers are choosing the optimal strategy for treatment of stage IIIA-N2 NSCLC. First, the results of our study demonstrate that careful selection of patients with N2 disease for induction therapy followed by surgery can lead to excellent outcomes. Of note, the 5-year survival of $41 \%$ found in our study for both the IC and ICR groups is better than the $15.7 \%$ and $27 \%$ 5-year survival of the surgery arms for trials EORTIC (European Organisation for Research and Treatment of Cancer) 8941 and INT0139 (phase III randomized controlled trials evaluating the role of surgery after induction therapy in the treatment of $\mathrm{N} 2$ NSCLC), respectively. ${ }^{19,25}$ Second, because we showed no difference in overall survival between treatment groups, there may be a number of potential advantages to using chemotherapy alone in induction regimens: (1) higher delivery of preoperative chemotherapy, which may contribute to improved survival; (2) more accurate assessment of the tumor's response to chemotherapy; and (3) lower perioperative complication rates. ${ }^{7}$ Of note, adding radiation to IC is associated with higher rates of acute toxicity and increased cost. ${ }^{6}$

\section{Study Limitations}

There are several limitations to this study that are inherent to analyses of patients with stage IIIA in the NCDB, as previously reported, ${ }^{9}$ which include its retrospective nature and possible incompleteness of data. The NCDB also does not have data on the extent of mediastinal lymph node dissection, the number of $\mathrm{N} 2$ stations dissected, the details regarding radiation type and technique, the local and distant recurrence and diseasefree survival, and the performance status of patients at different time points before neoadjuvant or adjuvant therapies. This NCDB analysis also had missing data on pathologic $\mathrm{T}$ and $\mathrm{N}$ status for a significant number of patients.

In addition, it is unclear how many patients in our cohort had biopsy-proven N2 disease because the NCDB does not provide detailed information regarding invasive mediastinal staging before induction therapy or surgery. Because of this limitation of the NCDB, there is a possibility that the patients included in the present study were overstaged, although there is no particular reason to suspect a difference in overstaging between the groups.

Because of the possibility of overstaging, the downstaging rates reported in the present study should be interpreted with caution, although the rates we found are comparable to those reported by other randomized trials. ${ }^{4,19}$ In addition, there is a possibility that overstaging contributed to the higher survival seen in the present study when compared with survival reported from previous randomized trials (eg, EORTC 8941 and Intergroup 0139), although the accrual period of those trials was older than the present study time period, and differences in patient selection, staging/restaging, and operative strategies between previous trials and the present study could have accounted at least in part for differences in survival seen between the present study and previous trials. We can only speculate and infer from recent survey results, ${ }^{6}$ but presumably the present study reflects a more contemporary practice pattern in which surgeons mostly operate only on single-station, microscopic N2 disease; patients undergo brain imaging as part of the initial preoperative assessment; staging and 
restaging with positron emission tomography/computed tomography are more common; and use of pneumonectomy is more selective and infrequent.

The intrinsic limitations of the NCDB data also do not allow us to accurately determine the number of patients who were intended to proceed to surgery after induction therapy but who did not. This may have biased our results if there was a difference in the likelihood of completing induction therapy and subsequently undergoing surgery between the IC and ICR groups.

Finally, the NCDB does not distinguish between "bulky" versus "nonbulky" $\mathrm{N} 2$ disease and single-station versus multi-station $\mathrm{N} 2$ disease. It is possible that ICR actually improves survival but that we did not see a difference in survival between ICR and IC because the ICR group had worse N2 disease. To explore this possibility, we evaluated practice patterns of hospitals across the United States, and we found that for stage IIIA-N2 disease, approximately $76 \%$ of hospitals used primarily IC or ICR. This finding suggests that the decision to treat a patient with IC or ICR may be based more on institution philosophy and less on individual patient factors (eg, whether a patient had microscopic vs bulky N2 disease). We also evaluated the survival of patients with cT1N2 and patients with pT0N0 disease following induction therapy who underwent lobectomy with the assumption that these patients would more likely have single-station or microscopic $\mathrm{N} 2$ disease and that in these subgroups there would be a fairly even distribution of single station or microscopic N2 disease between the IC and ICR groups. We acknowledge that there are flaws with this assumption, but there have been some data from early-stage NSCLC suggesting that the frequency of lymph node metastases increases as the tumor size increases. ${ }^{26}$ In these subset analyses, we found no differences in survival between the IC and ICR groups. The results of these two exploratory analyses should be interpreted with caution, but they do provide some evidence suggesting that our primary finding that there is no significant difference in overall survival between IC and ICR is at least not entirely due to patients in the ICR group having significantly worse N2 disease when compared with the IC group.

\section{CONCLUSIONS}

In this NCDB analysis, ICR was used in the majority of patients who had induction therapy before surgical resection of clinical stage IIIA-N2 NSCLC. The addition of induction radiation was not associated with improved survival when compared with IC. Given the key limitations of this present study noted earlier, the use of ICR for operable stage IIIA-N2 NSCLC should be further reexamined in the context of randomized trials, and future prospective and retrospective studies should focus on identifying characteristics (eg, single-station vs multi-station $\mathrm{N} 2$ disease) that can be used to indicate if and when radiation is needed in addition to chemotherapy. Multidisciplinary evaluation and discussion of treatment options for patients with stage IIIA-N2 NSCLC are essential before operative intervention.

\section{Conflict of Interest Statement}

T.A.D. serves as a consultant for Scanlan International, Inc. All other authors have nothing to disclose with regard to commercial support.

You can watch a Webcast of this AATS meeting presentation by going to: http://webcast.aats.org/2015/ Video/Monday/04-27-15_6C_1555_Yang.mp4

The data used in this study are derived from a de-identified NCDB file. The American College of Surgeons and the Commission on Cancer have not verified and are not responsible for the analytic or statistical methodology used, or the conclusions drawn from these data by the investigators. The authors thank Brandon Yan for his assistance in this study.

\section{References}

1. Roth JA, Atkinson EN, Fossella F, Komaki R, Bernadette Ryan M, Putnam JB Jr, et al. Long-term follow-up of patients enrolled in a randomized trial comparing perioperative chemotherapy and surgery with surgery alone in resectable stage IIIA non-small-cell lung cancer. Lung Cancer. 1998;21:1-6.

2. Rosell R, Gomez-Codina J, Camps C, Javier Sanchez J, Maestre J, Padilla J, et al. Preresectional chemotherapy in stage IIIA non-small-cell lung cancer: a 7-year assessment of a randomized controlled trial. Lung Cancer. 1999;26:7-14.

3. Thomas M, Rube C, Hoffknecht P, Macha HN, Freitag L, Linder A, et al. Effect of preoperative chemoradiation in addition to preoperative chemotherapy: a randomised trial in stage III non-small-cell lung cancer. Lancet Oncol. 2008;9: 636-48.

4. Pless M, Stupp R, Ris H, Stahel R, Weder W, Thierstein S, et al. Neoadjuvant chemotherapy with or without preoperative irradiation in stage IIIA/N2 nonsmall cell lung cancer (NSCLC): a randomized phase III trial by the Swiss Group for Clinical Cancer Research (SAKK trial 16/00). J Clin Oncol. 2013;31(suppl; abstr 7503)

5. Ripley RT, Rusch VW. Role of induction therapy: surgical resection of non-small cell lung cancer after induction therapy. Thorac Surg Clin. 2013;23:273-85.

6. Ettinger DS, Akerley W, Borghaei H, Chang AC, Cheney RT, Chirieac LR, et al. Non-small cell lung cancer. J Natl Compr Canc Netw. 2012;10:1236-71.

7. Shah AA, Berry MF, Tzao C, Gandhi M, Worni M, Pietrobon R, et al. Induction chemoradiation is not superior to induction chemotherapy alone in stage IIIA lung cancer. Ann Thorac Surg. 2012;93:1807-12.

8. Berry MF, Worni M, Pietrobon R, D’Amico TA, Akushevich I. Variability in the treatment of elderly patients with stage IIIA (N2) non-small-cell lung cancer. J Thorac Oncol. 2013;8:744-52.

9. Sher DJ, Liptay MJ, Fidler MJ. Prevalence and predictors of neoadjuvant therapy for stage IIIA non-small cell lung cancer in the National Cancer Database: importance of socioeconomic status and treating institution. Int J Radiat Oncol Biol Phys. 2014;89:303-12

10. Greene FL, American Joint Committee on Cancer. American Cancer Society. AJCC Cancer Staging Manual. New York: Springer; 2002.

11. Sauvaget J, Rebischung JL, Vannetzel JM. Phase III study of neo-adjuvant MVP versus MVP plus chemoradiotherapy in stage III NSCLC (abstract 1935). Proc Am Soc Clin Oncol. 2000;19.

12. Fleck J, Camargo J, Godoy D, Teixeira P, Braga-Filho A, Barietta A, et al. Chemoradiation therapy (CRT) versus chemotherapy (CT) alone as a neoadjuvant treatment for stage III non-small cell lung cancer (NSCLC) preliminary report of a phase III prospective randomized trial (abstract 1108). Proc Am Soc Clin Oncol. 1993;12.

13. Girard N, Mornex F, Douillard JY, Bossard N, Quoix E, Beckendorf V, et al Is neoadjuvant chemoradiotherapy a feasible strategy for stage IIIA-N2 non-small cell lung cancer? Mature results of the randomized IFCT-0101 phase II trial. Lung Cancer. 2010;69:86-93.

14. Higgins K, Chino JP, Marks LB, Ready N, D’Amico TA, Clough RW, et al. Preoperative chemotherapy versus preoperative chemoradiotherapy for stage 
III (N2) non-small-cell lung cancer. Int J Radiat Oncol Biol Phys. 2009;75: 1462-7.

15. Li J, Dai CH, Shi SB, Chen P, Yu LC, Wu JR. Prognostic factors and long term results of neo adjuvant therapy followed by surgery in stage IIIA N2 non-small cell lung cancer patients. Ann Thorac Med. 2009;4:201-7.

16. Pezzetta E, Stupp R, Zouhair A, Guillou L, Taffe P, von Briel C, et al. Comparison of neoadjuvant cisplatin-based chemotherapy versus radiochemotherapy followed by resection for stage III (N2) NSCLC. Eur J Cardiothorac Surg. 2005;27:1092-8.

17. Mordant P, Fabre E, Gibault L, Arame A, Pricopi C, Dujon A, et al. [Impact of induction therapies on pathology and outcome after surgical resection of non-small lung cancer: a 30-year experience of 859 patients]. Rev Pneumol Clin. 2014;70:9-15.

18. Jaklitsch MT, Gu L, Demmy T, Harpole DH, D’Amico TA, McKenna RJ, et al. Prospective phase II trial of preresection thoracoscopic mediastinal restaging after neoadjuvant therapy for IIIA (N2) non-small cell lung cancer: results of CALGB Protocol 39803. J Thorac Cardiovasc Surg. 2013;146:9-16.

19. Albain KS, Swann RS, Rusch VW, Turrisi AT III, Shepherd FA, Smith C, et al. Radiotherapy plus chemotherapy with or without surgical resection for stage III non-small-cell lung cancer: a phase III randomised controlled trial. Lancet. 2009; 374:379-86.

20. Daly BD, Fernando HC, Ketchedjian A, DiPetrillo TA, Kachnic LA, Morelli DM, et al. Pneumonectomy after high-dose radiation and concurrent chemotherapy for nonsmall cell lung cancer. Ann Thorac Surg. 2006;82:227-31.

21. Donington JS, Pass HI. Surgical resection of non-small cell lung cancer with N2 disease. Thorac Surg Clin. 2014;24:449-56.

22. Gaissert HA, Keum DY, Wright CD, Ancukiewicz M, Monroe E, Donahue DM, et al. POINT: Operative risk of pneumonectomy-Influence of preoperative induction therapy. J Thorac Cardiovasc Surg. 2009;138:289-94.

23. Weder W, Collaud S, Eberhardt WE, Hillinger S, Welter S, Stahel R, et al Pneumonectomy is a valuable treatment option after neoadjuvant therapy for stage III non-small-cell lung cancer. J Thorac Cardiovasc Surg. 2010;139:1424-30.

24. Mansour Z, Kochetkova EA, Ducrocq X, Vasilescu MD, Maxant G, Buggenhout A, et al. Induction chemotherapy does not increase the operative risk of pneumonectomy! Eur J Cardiothorac Surg. 2007;31:181-5.

25. van Meerbeeck JP, Kramer GW, Van Schil PE, Javier Sanchez J, Maestre J, Padilla J, et al. Randomized controlled trial of resection versus radiotherapy after induction chemotherapy in stage IIIA-N2 non-small-cell lung cancer. J Natl Cancer Inst. 2007;99:442-50.

26. Seok Y, Yang HC, Kim TJ, Lee KW, Kim K, Jheon S, et al. Frequency of lymph node metastasis according to the size of tumors in resected pulmonary adenocarcinoma with a size of $30 \mathrm{~mm}$ or smaller. J Thorac Oncol. 2014;9:818-24.

Key Words: lung cancer surgery, neoadjuvant therapy

\section{Discussion}

Dr D. Jones (New York, NY). I have 2 questions for you. Most of the upside of using administrative databases such as this is the large number of patients. The problem is, as you point out, we don't really know how many really had N2 disease. How should we in the audience accept that limitation of the study? Is this just real life, and can we take these data and say there really is no difference between chemoradiotherapy and chemotherapy as an induction strategy?

Dr Yang. As you noted, in the NCDB we do not have data regarding biopsy-proven pathologic N2 disease before induction therapy. We think that in the real-world setting there is probably a combination of clinical staging and pathologic staging before surgeons or oncologists make the decision for induction therapy, but the lack of data regarding biopsy-proven pathologic N2 disease is a major limitation for this study. However, our findings at least suggest that induction radiation can be used selectively, as opposed to universally, in patients clinically staged with N2 disease.

Dr Jones. I noticed there was no significant difference in survival with presumed N2 downstaging. Did that hold true for both the IC alone and the ICR groups? Did you look at that?

Dr Yang. Yes. I think you are referring to previous studies showing that patients who are downstaged are more likely to have improved survival. We did see this in both the IC and ICR groups. When we looked at patients who had IC, the patients who received nodal downstaging had improved survival.

Dr Jones. Thank you.

Dr P. De Leyn (Leuven, Belgium). Although you didn't always have pathologic proof of the nodes, your study confirms what many centers in Europe believe, namely, that for N2 disease you don't need ICR. In 2008, Thomas published a multicenter German trial in patients with proven $\mathrm{N} 2$ and even N3 disease and compared ICR with IC. They found more nodal downstaging but no effect on survival. This proves what your study also shows. It is a very nice study.

Dr Yang. Thank you.

Dr J. Sonett (New York, NY). As we talked about, nodal downstaging through practically every prospective trial has reflected an overall better survival. Now, the nodal downstaging in this was 58\% for chemotherapy alone. That is basically unheard of. Usually the best chemotherapy alone induction would be $20 \%$ to maybe $30 \%$. This may reflect some of the pathologic misnomer or problems with using a database that included those who weren't N2-positive, because nobody gets a $58 \%$ response rate to chemotherapy alone and now you are comparing those, so it sort of muddles up the whole answer of who was really N2 if you are including them, and that is my biggest worry. In terms of the Thomas study, which was an excellent prospective study, the issues with that study are that more than $60 \%$ had IIIB disease and I think more than $46 \%$ were pneumonectomies in the trial, which again muddies the water for our subset of resectable N2 with lobectomy.

Dr Yang. With regard to your first question on downstaging, for the present study we found that the clinical $\mathrm{N} 2$ to $\mathrm{pN} 0$ downstaging rate was actually $45 \%$ for the ICR group, which is comparable to the results reported by Intergroup 0139, which reported $46 \%$ for pathologic N2 to N0. Recently, there was a Swiss Group for Clinical Cancer Research 16/00 randomized controlled trial in Europe where they looked at IC versus sequential administration of IC and radiation, so it's slightly different from what we are looking at, but their downstaging rates reported were $53 \%$ for the IC alone group, which is comparable to the $\mathrm{N} 2$ to $\mathrm{pN} 0 / \mathrm{N} 1$ downstaging rate of $46 \%$ for our IC subset.

In terms of your second point about the Thomas study by the German Lung Cancer Cooperative Group, as you noted, 
there are limitations to that study, including the fact that approximately $44 \%$ of those patients never made it to resection, chemotherapy and radiation were given sequentially in the chemoradiation arm, and patients in the chemoradiation arm received more chemotherapy. The present study of the NCDB is different from the Thomas study in that we are looking more at real-world practice of patients who have undergone surgery after induction therapy and that in the United States, most patients who get ICR receive concurrent and not sequential chemoradiation.

Dr H. Date (Kyoto, Japan). My question is also regarding downstaging after induction treatment. In your study, overall survival did not show any improvement in patients who showed a downstaging, but you mentioned that after IC, there seemed to be some improvement, which means the improvement was not seen after ICR even if the patient showed a pathologic downstaging. That is my understanding. Is that true?

Dr Yang. Yes, sir.

Dr Date. Why is that?

Dr Yang. That is an important question and something that we have discussed extensively in our group, and we also appreciate the reviewers of our article for bringing to our attention further considerations. We have generated several different hypotheses. In the interest of time, I'm only going to focus on 2 . The first is that perhaps the patients who received ICR were more likely to have fewer doses of chemotherapy because of toxicity from radiation. For example, in the German Lung Cancer Cooperative Group trial by Thomas and colleagues, $10 \%$ of patients who received ICR had severe treatment-related hematotoxicity versus $0.5 \%$ of patients in the IC group. The second possibility is that we were underpowered to detect slight differences between the 2 groups. In our study, we had 870 deaths and a $90 \%$ power to detect an HR of 0.8 , but to detect an HR of 0.91 with an alpha of 0.5 and a power of $90 \%$, we would need 4600 events.

Dr D. Grunenwald (Paris, France). Congratulations on a very consistent study on more than 1000 patients and the clarity of your presentation. I am a bit surprised by the results. Last January, at the British Thoracic Oncology Group meeting in Dublin, a meta-analysis was presented on the randomized studies that have been on this topic. The article will be published soon by the Brompton group. Surprisingly, the results are exactly contrary to yours. Do you think it is a question of power of your retrospective study and randomized studies mainly done in the United States, in North America, or is it a question of methodology? Also, do you think that with your results you should change the practice in North America?

Dr Yang. I have not read the Brompton study that you referred to because it has not been published, but I will certainly do so once it is available. Perhaps there is some difference in methodologies in those trials that were included in the Brompton study. There is a published meta-analysis by Shah and colleagues earlier in 2012 that showed no difference between IC and ICR. With regard to your second question about changing practice here, we do understand that our present study has important limitations and that it is retrospective in nature, so I think our study highlights the need for further research on this topic in North America but also that radiation at least is not needed as a component of induction therapy in all patients with clinical N2 disease.

Dr R. Battafarano (Baltimore, $M d$ ). How many patients who received the IC only ended up getting radiation?

Dr Yang. That is an important question. I will need to look that up for you.

Dr Battafarano. The reason why I ask is that trimodality therapy is going to be chemotherapy, radiation, and surgery all mixed in. If you give IC, do the surgery, and then they all get radiation, compared with chemorads and then surgery followed by systemic chemotherapy, at the end of the day, they get all 3 modalities. Because most cancers are upper lobe cancers, the advantage of giving the radiation up front is that the radiation actually traverses, to get to the mediastinum, the lobe you take out, so if you give induction chemorads followed by a right upper lobectomy, the middle and lower lobes receive zero radiation essentially. If you give IC and then we do our lobectomy, we free up the inferior pulmonary ligament, and now the middle and lower lobes are going to be the pass-through lesions that get the radiation, if they do give adjuvant radiation. It really changes those functions. If I have a right upper lobe tumor, I would rather see all the radiation go through lung that is coming out rather than have them get into trouble with radiation pneumonitis to the lung you saved. But you are not really sure how many people got radiation after?

Dr Yang. We do have that information; 31\% received adjuvant radiation in the IC alone group.

Dr E. Vallieres (Seattle, Wash). I used to be a preoperative chemoradiation guy, but there are 2 European randomized studies that have concluded exactly as you have. There was a French trial by Sauvaget and colleagues, and although I have never seen the article, it was presented at the American Society of Clinical Oncology 2000. Two years ago, Pless and colleagues from the Swiss Group for Clinical Cancer Research in Switzerland, presented at the American Society of Clinical Oncology 2013 a cooperative group randomized study of chemotherapy versus chemoradiotherapy preoperatively for histologically documented IIIA N2 disease. Both randomized studies had the same observations you made, better nodal clearance with chemoradiation and more $\mathrm{R} 0$ resections, but, at the end, the survival was the same in both arms. The conclusion in the Swiss trial was that after IC, if you do a good operation to take care of the locoregional issues, you don't need radiation.

Dr Yang. Thank you for your comment. 